\title{
PENGARUH PENGGUNAAN LEG-GAITER SPLINT TERHADAP SPASTISITAS KNEE FLEXOR PADA PASIEN ANAK SPASTIC CEREBRAL PALSY
}

\author{
Muhammad Syaifuddin $^{1}$, S.Th Susilowati ${ }^{2}$, Angelia Vrecika ${ }^{3}$ \\ 1,2,3 Jurusan Ortotik Prostetik, Politeknik Kesehatan Surakarta \\ Email: aipud99@gmail.com, sth.susilowati@gmail.com,vrechiika@gmail.com
}

\begin{abstract}
Effect of Leg-Gaiter Splint to Knee Flexor's Spasticity in Children with Spastic Cerebral Palsy. Objective: to determine in there a effect of leg-gaiter splint to knee flexor's spasticity in children with spastic cerebral palsy. Subject: 20 children with spastic cerebral palsy. Research Place: Pediatric and Neurodevelopmental Treatment Centre. Research Time: January 2016 to March 2016. Measuring Instrument: Modified Ashworth Scale - Bohannon (MAS-B). Research Design: This research used a pre-experimental method, using one group pre-test and post-test design. Result: Normality test with Shapiro Wilk Test on pre-test result and post-test result showed the value is $p<0,05$ it means the data's abnormally distributed. Hyphotesis test with Wilcoxon Test showed that spasticity on the right leg has value $p=0,000(p<0,05)$ and spasticity on the left leg has value $p=0,000$ ( $p<0,05)$, it means there is significant difference between before using the leg-gaiter splint and after in decreasing the spasticity level of knee flexor. Conclusion: based on the analysis of the research has done, can be concluded that the application of leg-gaiter splint can give a significant difference for decreasing the spasticity level of knee flexor in children with spastic cerebral palsy.
\end{abstract}

Keywords: Spasticity, Leg-gaiter splint, Spastic cerebral palsy

\begin{abstract}
Abstrak: Pengaruh Penggunaan Leg-Gaiter Splint terhadap Spastisitas Knee Flexor pada Pasien Anak Spastic Cerebral Palsy. Tujuan: untuk mengetahui adakah pengaruh penggunaan leg-gaiter splint terhadap spastisitas knee flexor pada pasien anak spastic cerebral palsy. Subyek: 20 subyek spastic cerebral palsy. Tempat Penelitian: Pediatric and Neurodevelopmental Treatment Centre, Surakarta. Waktu penelitian: Januari 2016 - Maret 2016. Alat ukur: Modified Ashworth Scale - Bohannon (MAS-B). Desain penelitian: Penelitian ini menggunakan metode praeksperimental, dengan menggunakan one group pre-test and post-test design. Hasil: Uji normalitas menggunakan Shapiro-wilk test pada pre-test dan post-test menunjukkan nilai $\mathrm{p}<0,05$, maka data berdistribusi tidak normal. Uji hipotesis menggunakan wilcoxon dengan hasil spastisitas pada tungkai kanan $\mathrm{p}<0,05$ dan hasil spastisitas pada tungkai kiri $\mathrm{p}<0,05$ maka terdapat pengaruh penggunaan leg-gaiter splint pada spastisitas pasien anak spastic cerebral palsy. Kesimpulan: berdasarkan analisis penelitian yang telah dilakukan dapat disimpulkan bahwa penggunaan leggaiter splint menurunkan derajat spastisitas knee flexor pada pasien anak spastic cerebral palsy.
\end{abstract}

Kata kunci: Spastisitas, Leg-gaiter splint, Spastic cerebral palsy.

Kehadiran anak sangat ditunggu-tunggu setiap kali pernikahan tercatat secara resmi oleh negara. Kelahiran seorang bayi yang sehat, normal secara fisik dan jiwa merupakan harapan besar bagi mereka yang begitu menantikan kehadiran penerus keluarganya. Tuhan memiliki rencana lain, anak yang dititipkan tidak seperti idaman orang tuanya, anak tersebut mengalami gangguan perkembangan,

Cerebral palsy merupakan sebuah kelumpuhan saraf permanen tidak progresif yang mengakibatkan gangguan pada pergerakan dan postur tubuh. Tipe cerebral palsy yang sering dialami adalah spastic cerebral palsy, sekitar
$80 \%$ penderita cerebral palsy berada pada tipe spastic (Novak, 2014).

Spastisitas merupakan keadaan dimana tonus otot meningkat (hypertonus). Penderita spastic cerebral palsy akan mengalami kekakuan pada ototnya tanpa adanya kontrol dari otak, yang mengakibatkan anggota gerak tubuh mengalami pergerakan tidak terkontrol secara tiba-tiba dan limited movement (Dimitrijevic, 2014).

Bagi pasien cerebral palsy anak, pemberian intervensi ortosis untuk kasus spastisitas memiliki peranan yang sangat penting untuk perkembangan tubuh anak dan 
mengoptimalkan fungsi mekanis anak tersebut (Charlton dan Ferguson, 2008).

Leg-gaiter splint merupakan salah satu jenis Knee Orthosis, cakupannya hanya sekitar sendi lutut, tidak lebih.

Prinsip utama pemakaian leg-gaiter splint adalah untuk mencegah terjadinya kneehyperextension pada kasus extensor tone dan mencegah knee flexion pada kasus flexor tone. Untuk itu, perlu dilakukan re-align knee joint sedekat mungkin dengan posisi normal knee joint (Charlton dan Ferguson, 2008).

\section{METODE PENELITIAN}

\section{Rancangan Penelitian}

Rancangan penelitian menggunakan metode pra-eksperimental dengan menggunakan rancangan one group pre-test and post test. Dalam penelitian digunakan satu kelompok yang diteliti tanpa adanya kelompok pembanding.

Penelitian ini bertujuan untuk mengteahui pengaruh penggunaan leg-gaiter splint terhadap spastisitas knee flexor pada pasien anak spastic cerebral palsy.

\section{Populasi dan Sampel}

Populasi penelitian ini yaitu pasien anak di Pediatric and Neurodevelopmental Treatment Centre Surakarta usia 1-12 tahun. Penelitian berlangsung selama tiga bulan dengan frekuensi pemakaian leg-gaiter splint selama satu jam dalam satu hari selama bulan Januari 2016 hingga Maret 2016.

Penetapan sampel sebanyak 20 responden yang diambil dengan metode purposive sampling.

\section{Instrumen Penelitian}

Instrumen penelitian yang digunakan dalam penelitian ini adalah: a. formulir penelitian, b. alat tes skala ashworth yang telah dimodifikasi, c. leg-gaiter splint.

\section{Tahap I. Tahap Pemberian Edukasi}

Pada tahap ini, peneliti memberikan edukasi kepada pasien beserta orang tua atau pendamping tentang maksud dan tujuan penelitian.

\section{Tahap II. Tahap Pengukuran Derajad Spastisitas Sebelum Perlakuan}

Pada tahap ini peneliti melakukan pengukuran derajad spastisitas dengan dibantu oleh fisioterapis dengan menggunakan skala ashworth yang dimodifikasi.
Tahap III. Tahap Pemberian Intervensi LegGaiter Splint

Pada tahap ini peneliti memberikan perlakuan/intervensi berupa pemakaian alat bantu leg-gaiter splint pada responden dengan memberi pengarahan pemakaian.

\section{Tahap IV. Pengumpulan Data}

Tahap pengumpulan data dilakukan tiga bulan kemudian setelah pemberian intervensi. Pengumpulan data dilakukan dengan cara memeriksa dan emngukur derajad spastisitas responden dengan bantuan fisioterapis menggunakan skala ashowrth yang dimodifikasi.

\section{Tahap V. Analisis Data}

Hasil data pre-test dan post-test kemudian dilakukan pengolahan menggunakan program statistic kompyter SPSS versi 23. Untuk uji normalitas menggunakan Shapiro-Wilk Test dikarenakan responden kurang dari 50. Uji hipotesis menggunakan Wilcoxon.

\section{HASIL}

\section{Gambaran Umum Subyek Penelitian}

Distribusi umur subyek penelitian dapat dilihat pada tabel 1, dan jenis kelamin subyek penelitian pada tabel 2 .

Tabel 1.Distribusi Umur Subyek Penelitian

\begin{tabular}{ccr}
\hline Umur & $\mathbf{n}$ & \% \\
\hline 1 & 1 & 5,0 \\
\hline 2 & 2 & 10,0 \\
\hline 3 & 4 & 20,0 \\
\hline 4 & 2 & 10,0 \\
\hline 5 & 4 & 20,0 \\
\hline 7 & 3 & 15,0 \\
\hline 8 & 2 & 10,0 \\
\hline 9 & 1 & 5,0 \\
\hline 11 & 1 & 5,0 \\
\hline Jumlah & 20 & 100,0 \\
\hline
\end{tabular}

Tabel 2. Jenis Kelamin Subyek Penelitian

\begin{tabular}{ccc}
\hline Klasifikasi Jenis & \multicolumn{2}{c}{ Kelompok } \\
\cline { 2 - 3 } Kelamin & Jumlah & Persentase (\%) \\
\hline Laki-laki & 9 & 45 \\
\hline Perempuan & 11 & 55 \\
\hline Jumlah & 20 & 100 \\
\hline
\end{tabular}




\section{Uji Normalitas}

Uji statistic untuk mengetahui normalitas data menggunakan Shapiro-Wilk Test. Hasil uji pada data pre-test baik untuk tungkai kiri maupun tungkai kanan adalah $p<0,05$ maka dikatakan data berdistribusi tidak normal. Hasil uji normalitas untuk data post-test baik tungkai kiri maupun tungkai kanan adalah $p<0,05$, maka data juga berdistribusi tidak normal.

bawah ini:

Hasil uji dapat dilihat pada tabel di

Tabel 3. Uji Normalitas Shapiro-Wilk

\begin{tabular}{|c|c|}
\hline Variabel & Nilai $p$ \\
\hline Pre-test spastisitas tungkai kanan &, 000 \\
\hline $\begin{array}{l}\text { Post-test spastisitas tungkai } \\
\text { kanan }\end{array}$ & ,001 \\
\hline Pre-test spastisitas tungkai kiri &, 010 \\
\hline Post-test spastisitas tungkai kiri &, 002 \\
\hline
\end{tabular}

\section{Uji Hipotesis}

Dari hasil uji normalitas, dikarenakan distribusi data tidak normal, maka menggunakan Wilcoxon Test untuk menguji hipotesis.

Hasil uji hipotesis berupa 19 responden mengalami penurunan derajad spastisitas pada masing-masing tungkai dari total 20 responden. Terdapat satu responden yang mengalami peningkatan derajad spastisitas pada tungkai kanan, sedangkan tungkai kiri tidak mengalami perubahan.

Tabel 4. Uji Hipotesis

\begin{tabular}{lccc}
\hline & Ranks & $\mathrm{n}$ \\
\hline \multicolumn{2}{l}{ Spastisitas post-test tungkai } & Negative & 19 \\
kanan-spastisitas & pre-test & Positif & 1 \\
tungkai kanan & & Ties & 0 \\
& & Total & 20 \\
\hline \multicolumn{2}{l}{ Spastisitas post-test tungkai } & Negative & 19 \\
kiri-spastisitas pre-test & Positif & 0 \\
tungkai kiri & & Ties & 1 \\
& & Total & 20 \\
\hline
\end{tabular}

Dari hasil uji hipotesis Wilcoxon untuk mengetahui perubahan derajat spastisitas sebelum dan sesudah pemakaian leg-gaiter splint selama satu jam dalam satu hari didapatkan hasil dengan nilai $\mathrm{z}=-3,962$ dan $-4,264$ dengan nilai $p<0,05$.

\begin{tabular}{lcc}
\hline & $\mathrm{Z}$ & Nilai $p$ \\
\hline $\begin{array}{l}\text { Spastisitas post-test } \\
\text { tungkai kanan-spastisitas } \\
\text { pre-test tungkai kanan }\end{array}$ & $-3,962$ & 0,000 \\
\hline $\begin{array}{l}\text { Spastisitas post-test } \\
\text { tungkai kiri-spastisitas pre- } \\
\text { test tungkai kiri }\end{array}$ & & \\
\hline
\end{tabular}

\section{PEMBAHASAN}

Penelitian ini merupakan penelitian praeksperimental untuk mengetahui pengaruh penggunaan leg-gaiter split terhadap spastisitas knee flexor pada pasien anak spastic cerebral palsy. Populasi penelitian ini adalah pasien cerebral palsy yang menjalani rawat jalan di Pediatric and Developmental Treatment Centre periode Januari 2016 sampai dengan Maret 2016 dan memenuhi criteria inklusi yang telah ditetapkan oleh peneliti. Hasil observasi didapatkan 20 pasien spastic cerebral palsy.

\section{Faktor Usia}

Menurut hasil penelitian umur subyek terbanyak berumur tiga tahun dan lima tahun sebanyak masing-masing empat orang (20\%).

Hal ini didukung oleh penelitian yang dilakukan oleh El_Zahwary bahwa di Eropa dan Amerika Serikat prevalensi cerebral palsy pada umur 5-14 tahun akan mencapai puncaknya dan selanjutnya akan menurun.

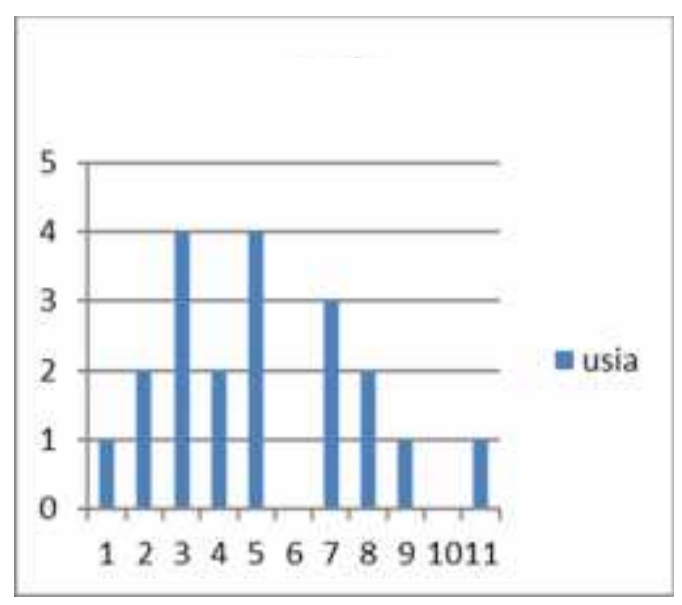

Grafik 1. Faktor Usia 


\section{Pengaruh Penggunaan Leg-Gaiter Splint terhadap Spastisitas Knee Flexor Tungkai Kanan}

Hasil penelitian menunjukkan bahwa penggunaan leg-gater splint mempunyai pengaruh yang signifikan terhadap spastisitas knee flexor pada tungkai kanan, hal ini terlihat dari hasil penelitian yang mana menunjukkan bahwa pasien yang menggunakan leg-gaiter splint pada tungkai kanan mempunyai nilai ratarata spastisitas saat pre-test 2,85 dan post-test 1,90 dan data dikatakan tidak normal karena terdapat sebaran data yang jauh dari garis. Seperti tertera pada diagram dibawah ini:
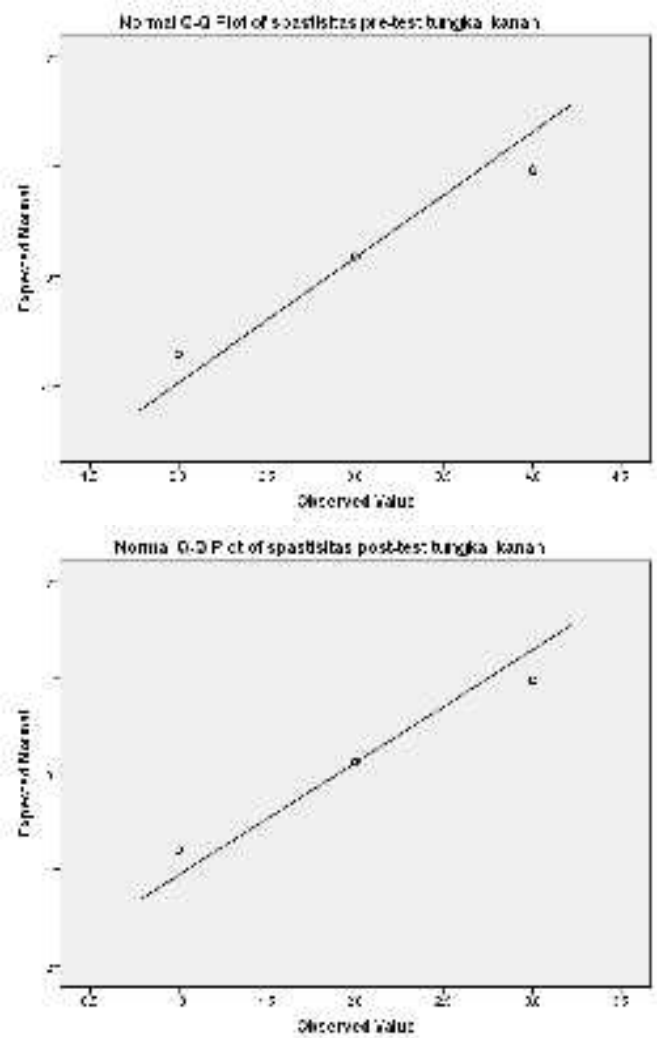

\section{Pengaruh Penggunaan Leg-Gaiter Splint terhadap Spastisitas Knee Flexor Tungkai Kiri}

Hasil penelitian menunjukkan bahwa penggunaan leg-gaiter splint mempunyai pengaruh yang signifikan terhadap spastisitas knee flexor pada tungkai kiri, hal ini terlihat dari hasil penelitian yang mana menunjukkan bahwa pasien yang menggunakan leg-gaiter splint pada tungkai kiri mempunyai nilai rata-rata spastisitas saat pre-test 2,95 dan post-test 1,95 dan data dikatakan tidak normal karena terdapat sebaran data yang jauh dari garis. Seperti tertera pada diagram dibawah ini:

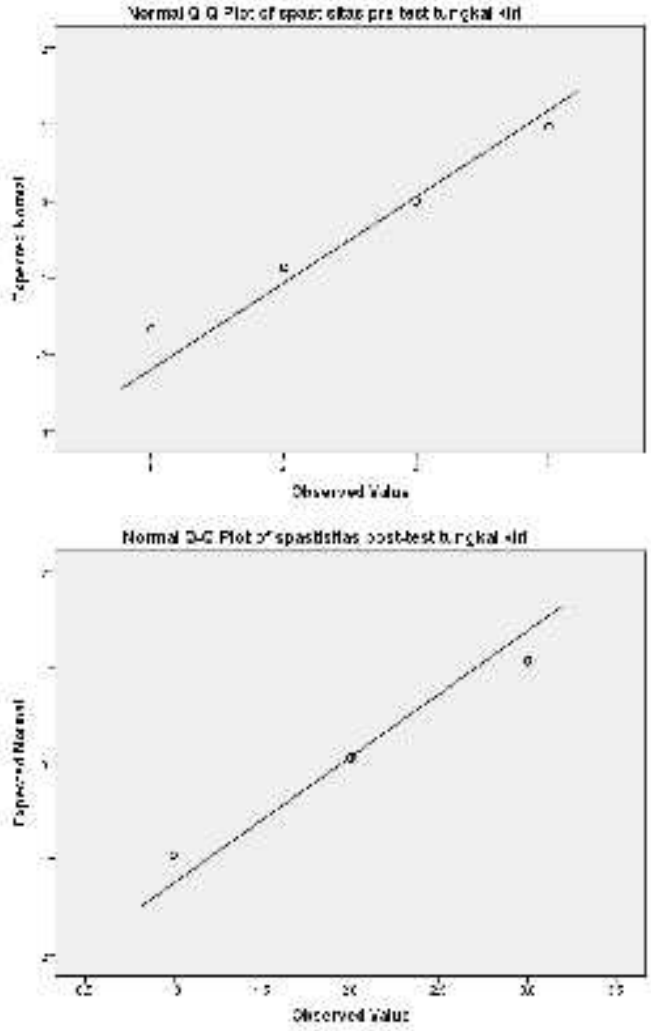

Hasil uji hipotesis Wilcoxon Test pada pre-test dan post-test masing-masing tungkai didapatkan pada tungkai kanan $p=0,000(p<0,05)$ dan tungkai kiri $p=0,000(p<0,05)$ yang berarti terdapat pengaruh yang bermakna terhadap spastisitas knee flexor kedua tungkai. Dengan detail pada masing-masing tungkai terdapat 19 responden yang mengalami penurunan derajad spastisitas dan satu responden dengan peningkatan spastisitas pada tungkai kanan dan tidak ada perubahan derajad sepastisitas pada tungkai kiri.

Intervensi pemberian leg-gaiter splint dapat menurunkan derajad spastisitas pada pasien anak spastic cerebral palsy.

\section{SIMPULAN}

Penelitian tentang pengaruh penggunaan leg-gaiter splint terhadap spastisitas knee flexor pada pasien anak spastic cerebral palsy yang dilakukan di PNTC Surakarta dengan jumlah responden 20 orang didapat kesimpulan bahwa terdapat pengaruh penggunaan leg-gaiter splint terhadap spastisitas knee flexor pada pasien anak spastic cerebral palsy.

Hasil uji Wilcoxon Test adalah Z=-3,962 dengan $p=0,000$ pada tungkai kanan dan $Z=-$ 4,264 dengan $p=0,000$, karena $p<0,05$, maka dapat dikatakan bahwa terdapat pengaruh penggunaan leg-gaiter splint terhadap spastisitas 
knee flexor pada pasien anak spastic cerebral palsy.

\section{SARAN}

Mengingat kelemahan yang ada pada penelitian ini, disarankan untuk dilakukan penelitian lanjut dengan memperhatikan: (1) subyek penelitian yang lebih merata dan tidak terbatas pada satu tempat saja, (2) variabel yang berbeda (3) desain penelitian yang lain.

\section{DAFTAR PUSTAKA}

Charlton, P. T., \& Ferguson, D. W. 2001. Orthosis, Splinting and Casting in Spasticity. In M. P. Barnes, \& G. R. Johnson, Upper Motor Neuron Syndrome and Spasticity : Clinical Management and Neurophysiology (pp. 142-164). Cambridge: The Press Syndicate of The Unicersity of Cambridge.

Dhillon, M. 2012. First Aid \& Management in Orthopaedic Injuries. New Delhi: Jaypee Brothers Medical Publishers.

Dimitrijevic, L. 2014. Assessment and Treatment of Spasticity in Children with Cerebral Palsy. Scientific Journal of the Faculty of Medicine, 163-169.

Edelstein, J. E., \& Bruckner, J. 2001. Orthotics: A Comprehensive Clinical Approach. United States Of America: SLACK Incorporated.

Flandry, F., \& Hommel, G. 2011. Normal Anatomy and Biomechanics of the Knee. Sports Med Arthorsc, 82-92.

Hinchcliffe, A. 2007. Children with Cerebral Palsy: A Manual for Theraphists, Parents and Community Workers. New Delhi: Sge Publications.

Holt, K. S. 1991. Everyday Aids and Appliances : Mobility Aids and Appliances for Disabled Children. Institue of Child Health, 105107.

Kerem, M., \& Topcu, M. 2001. Effects of Johnstone Pressure Splints Combined with Neurodevelopmental Therapy on Spasticity and Cutaneous Sensory Inputs in Spastic Cerebral Palsy. Developmental Medicine \& Child Neurology, 307-313.

Matters, A. 2014. Leg and arm gaiters. http://www.abilitymatters.co.uk/leg-andarm-gaiters-immobilisers.html.

Minear, W. 2012. Special Article: A Classification of Cerebral Palsy. Pediatrics
Official Journal of the American Academy of Pediatric, 841-853.

Morris, C. 2002. Orthotic Management of Children with Cerebral Palsy. American Academy of Orthotists \& Prosthetists, 150158.

Novak, I. 2012. Evidence-Based Diagnosis, Health Care, and Rehabilitation for Children with Cerebral Palsy. Journal of Child Neurology, 1141-1156.

Palisano, Robert; Rosenbaum, Peter; Bartlett, Doreen; Livingston, Michael;. (2007). GMFCS - E \& R : Gross Motor Function Classification System-Expanded and Revised. Can Child Centre for Childhood Disability Research , 1-4.

Prof. Dr. H. Punaji Setyosari, M. 2010. Metode Penelitian Pendidikan dan Pengembangan. Jakarta: Prenada Media Group.

Raj, G. S. 2006. Physiotherapy in Neuroconditions. New Delhi: Jaypee Brothers Medical Publishers.

Sankar, C., \& Mundkur, N. 2005. Cerebral PalsyDefinition, Classification, Etiology and Early Diagnosis. Indian Journal of Pediatric Vol. 72, 865-868.

Shamley, D. 2005. Pathophysiology An Essential Text for the Allied Health Professions. Philadelphia: Elsevier Butterworth Heinemann.

Shamsoddini, A., Amirsalari, S., Hollisaz, M.-T., Rahimnia, A., \& Khatibi-Aghda, A. 2014. Management of Spasticity with Cerebral Palsy. Iranian Journal of Pediatric, 345.

Singh, I. 2009. Essentials of Antomy. Second Edition. New Delhi: Jaypee Brothers Medical Publishers.

Stevenson, V. L., \& Louise, J. 2006. Spasticity Management: $\quad A \quad$ Practical Informa Healthcare. Multidisciplinary Guide. United Kingdom: 